\title{
Combined vertical-velocity observations with Doppler lidar, cloud radar and wind profiler
}

\author{
J. Bühl ${ }^{1}$, R. Leinweber ${ }^{2}$, U. Görsdorf ${ }^{2}$, M. Radenz ${ }^{1}$, A. Ansmann ${ }^{1}$, and V. Lehmann ${ }^{2}$ \\ ${ }^{1}$ Institute for Tropospheric Research (TROPOS), Permoserstr. 15, 04318 Leipzig, Germany \\ ${ }^{2}$ Deutscher Wetterdienst, Meteorologisches Observatorium Lindenberg (MOL), \\ Am Observatorium 12, 15848 Tauche, Germany \\ Correspondence to: J. Bühl (buehl@tropos.de)
}

Received: 9 December 2014 - Published in Atmos. Meas. Tech. Discuss.: 12 January 2015

Revised: 8 July 2015 - Accepted: 25 July 2015 - Published: 31 August 2015

\begin{abstract}
Case studies of combined vertical-velocity measurements of Doppler lidar, cloud radar and wind profiler are presented. The measurements were taken at the Meteorological Observatory, Lindenberg, Germany. Synergistic products are presented that are derived from the vertical-velocity measurements of the three instruments: a comprehensive classification mask of vertically moving atmospheric targets and the terminal fall velocity of water droplets and ice crystals corrected for vertical air motion. It is shown that this combination of instruments can up-value the measurement values of each single instrument and may allow the simultaneous sensing of atmospheric targets and the motion of clear air.
\end{abstract}

\section{Introduction}

Mixed-phase layered clouds are a critical component of the global weather and climate system. The occurrence of these clouds is difficult to predict, because the interaction between aerosols, cloud droplets and atmospheric dynamics is not understood. Errors in the prediction of layered clouds strongly affect the accuracy of global climate projections, because of their extended global appearance (D. Zhang et al., 2010; Y. Zhang et al., 2010).

Vertical motions of different scales are important for the development and the life-cycle of layered clouds. Large-scale atmospheric motions can influence the observations of an existing cloud decisively, e.g. by altering the vertical velocity of falling droplets or ice crystals. Furthermore, it was shown by Korolev and Field (2008) and recently by Simmel et al. (2014) that turbulent motion within the cloud layer can maintain its mixed-phase state, even if ice particles have formed that draw water vapor from the liquid droplets due to the Bergeron-Findeisen process. This large variety of scales and processes cannot be covered by a single instrument. Different efforts have been made to combine remote-sensing instruments in order to get a detailed picture of the processes involved in such mixed-phase layered clouds on small (Wandinger et al., 2012; Bühl et al., 2012, 2013) and large scales.

At the Meteorological Observatory Lindenberg (MOL) of the German Weather Service (DWD), a combination of lidars and a MIRA-35 cloud radar (Görsdorf et al., 2015) have been run for several years, especially in the context of Cloudnet (Illingworth et al., 2007). Additionally an ultra-highfrequency (UHF) wind profiler is being run operationally to retrieve the height-dependent advection speed of the air. Recently, a Streamline Doppler lidar of HALO Photonics company (Pearson et al., 2009; Lane et al., 2013; Päschke et al., 2015) has been added to this measurement suite. With the Doppler lidar, the cloud radar and the wind profiler, three instruments are combined that can study the movement of the air at different scales and a variety of conditions. The systems are collocated within a radius of $30 \mathrm{~m}$ and pointed vertical so that their observation volumes overlap. This combination and configuration of instruments is unique. Sets of similar radar instruments are available at other places (e.g., Tridon et al., 2013), but to our knowledge no combined measurements of Doppler lidar, cloud radar and wind profiler have been published so far. The UHF wind profiler at MOL allows the detection of vertical velocities up to about $8 \mathrm{~km}$ height (Böhme et al., 2004) by relatively long wavelength and high power in 
the mode of operation used in the context of this paper. Even larger heights (up to $16 \mathrm{~km}$ ) are available using a longer pulse length. The large height coverage is very important in our case, because in the mid-latitudes mixed-phase clouds most commonly occur in the height interval between 2 and $8 \mathrm{~km}$ (D. Zhang et al., 2010).

All three velocity-measuring instruments are most sensitive to particles or structures which are similar in size to the operating wavelength $\lambda$ of the instrument (see Table 1). The Doppler lidar $(\lambda=1.5 \mu \mathrm{m})$ is most sensitive to aerosol particles $(100 \mathrm{~nm}$ to $10 \mu \mathrm{m}$ in diameter). The cloud radar $(\lambda=8.5 \mathrm{~mm})$ is capable of sensing cloud droplets (10 to $100 \mu \mathrm{m})$. Additionally it shows large signals for hydrometeors like drizzle droplets, rain droplets or ice crystals $(100 \mu \mathrm{m}$ to $10 \mathrm{~mm}$ ). The wind profiler detects echoes from refractive index fluctuations originating from turbulent eddies in the atmosphere with sizes of half its wavelength of $\lambda=$ $0.62 \mathrm{~m}$ and Rayleigh scattering from particles. In this work, the combined operation of this unique set of instruments is demonstrated in order to study the vertical motions in and around layered clouds. The combination of wind profiler and cloud radar has been done before (Tridon et al., 2013). Protat and Williams (2011) also showed the principle of combined vertical-velocity observations, but with a combination of $50 \mathrm{MHz}$ wind-profiler and $3 \mathrm{GHz}$ radar. It is the focus of this paper to show that an additional Doppler lidar can deliver complementary information about the vertical velocity of small cloud droplets and their fast-changing turbulent motion. For that purpose, first tentative efforts of the MOL/TROPOS measurement campaign COLRAWI (Combined Observations with Lidar, Radar and Wind Profiler) are presented here. It is shown that turbulent air motion, largescale waves and the vertical movement of falling ice and water particles can be measured at once. In this way a coherent picture of different kinds of vertical motions in the atmosphere can be drawn and the unbiased fall velocity of particles can be measured.

This paper deals with first promising examples how to combine Doppler lidar, cloud radar and wind profiler. In Sect. 2 an overview is given about the three instruments and their simultaneous operation. In Sect. 3, case studies are presented and links between the data from the different instruments are established. A summary is given in Sect. 4.

\section{Overview about measurement instruments and strategy}

Wind-profiler radars have been designed to measure the wind speed in both the cloudy and clear atmosphere. While the radar technique itself is nearly 70 years old, the wind profiler technique was not developed before the 1970s (Woodman and Guillen, 1974; Strauch et al., 1984; Weber and Wuertz, 1990). A wind profiler exploits Bragg scattering at atmospheric density fluctuations to produce a backscatter signal

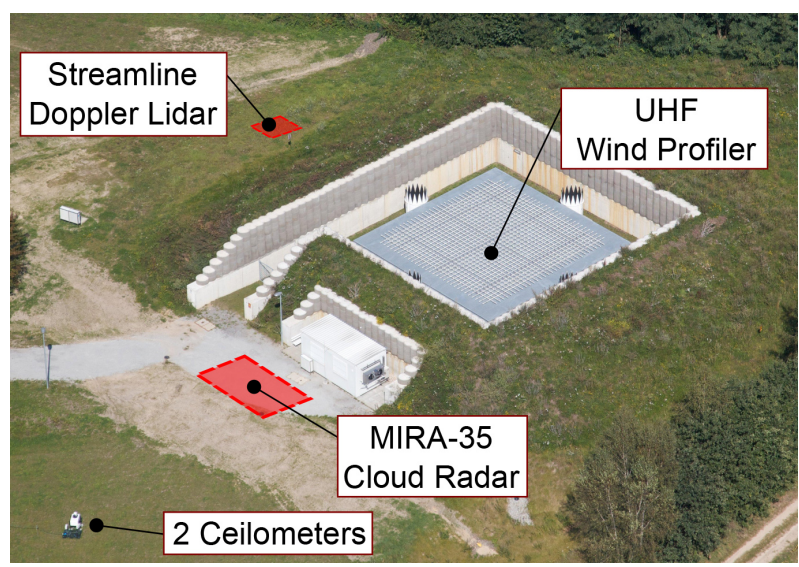

Figure 1. Aerial view of the wind profiler site at MOL. The photograph was taken in September 2011. In the meantime a Streamline Doppler lidar and a MIRA-35 cloud radar were deployed next to the wind profiler. During the measurements presented here, all instruments were pointing vertical at all times. Operational parameters of the systems measuring vertical velocity can be found in Table 1. (Bühl, 2015)

even under clear-air conditions. Rayleigh and Bragg scattering is proportional to $\lambda^{-4}$ and $\lambda^{-\frac{1}{3}}$, respectively.

Hence, Bragg scattering dominates more and more for longer wavelengths, but Rayleigh scattering from particles can still add to the signal. This Rayleigh-Bragg ambiguity limits the measurement of air motions in the presence of particles (Gage et al., 1999; Knight and Miller, 1998). Since particles are always falling with a certain velocity relative to the surrounding air, a bias towards negative velocities occurs, e.g., within cloud layers or rain. In Sect. 3.5 an outlook is given on a possible method to reduce this bias for the combination of cloud radar and wind profiler at MOL.

The distribution of powerful wind profilers is limited, but they can actually deliver the desperately needed information about the velocity of clear air. The DWD operates a UHF wind profiler at MOL (see Fig. 1). It works at $482 \mathrm{MHz}$ and can deliver wind information from $0.5 \mathrm{~km}$ to a maximum of $16 \mathrm{~km}$ height with a range resolution of $150 \mathrm{~m}$ and a measurement interval of about $10 \mathrm{~s}$ (Böhme et al., 2004). The distance between two neighboring range gates is $100 \mathrm{~m}$, due to range oversampling. Usually, the wind profiler is operated to derive the height-resolved horizontal wind with a four-beam Doppler beam-swinging technique. For the duration of the measurements presented here, Doppler lidar, cloud radar and wind profiler were always used in a vertical-stare mode.

Lidars and cloud radars can measure vertical velocity only if a sufficient number of aerosol particles, cloud droplets or ice crystals are present in the target volume. Under clearair conditions, no velocity information at all can be derived. In general, both instruments are therefore primarily used to derive information about particles. The main difference between the two instruments is the sensitivity towards different 
Table 1. Technical properties of the three main instruments involved in the combined measurements.

\begin{tabular}{llll}
\hline Designation & Doppler lidar & UHF Wind profiler & Cloud radar \\
\hline System type & HALO Streamline & LAP 16000 & MIRA-35 \\
\hline Wavelength & $1.5 \mu \mathrm{m}$ & $0.62 \mathrm{~m}$ & $8.5 \mathrm{~mm}$ \\
Pulse width & $160 \mathrm{~ns}$ & $1000 \mathrm{~ns}$ & $200 \mathrm{~ns}$ \\
Range gate length & $48 \mathrm{~m}$ & $94 \mathrm{~m}$ & $30 \mathrm{~m}$ \\
Integration time & $2 \mathrm{~s}$ & $10 \mathrm{~s}$ & $10 \mathrm{~s}$ \\
Beam width & $0.05 \mathrm{mrad}$ & $50 \mathrm{mrad}$ & $10 \mathrm{mrad}$ \\
Pulse repetition rate & $15 \mathrm{kHz}$ & $12.2 \mathrm{kHz}$ & $5 \mathrm{kHz}$ \\
Average emitted power & $200 \mathrm{~mW}$ & $200 \mathrm{~W}$ & $30 \mathrm{~W}$ \\
\hline
\end{tabular}

particle sizes. For droplets and ice crystals the Doppler lidar is operating in the geometrical optics regime and the signal response is proportional to the square of the particle diameter $D$. That makes the Doppler lidar especially sensitive for aerosol particles and cloud droplets. The cloud radar, on the other hand, operates in the Rayleigh regime due to its longer wavelength and is sensitive to $D^{6}$. The cloud radar signal is therefore easily dominated by larger particles in the observation volume, i.e., ice crystals or rain droplets. Within the context of this work, vertical velocity from cloud radar is always the reflectivity-weighted vertical velocity, i.e. the first moment of the cloud radar spectrum at a given range gate. Therefore, this value is mainly representing the vertical motion of the largest particles within the observation volume.

Hence, a combination of Doppler lidar, cloud radar and wind profiler enables the observation of a large variety of motions within the atmosphere from the turbulence within cloud layers, over the fall speed of large ice crystals towards the motion of air itself.

Table 1 shows the operational parameters of the main instruments for combined measurements of vertical velocity at MOL. All systems were co-located within a $30 \mathrm{~m}$ radius (see Fig. 1) and had therefore overlapping observation volumes. A schematic representation of the observation volumes is given in Fig. 2 illustrating the large technical differences between the three systems. In the context of this work, the Doppler lidar is operated with a measurement interval of $2 \mathrm{~s}$, cloud radar and wind profiler both with $10 \mathrm{~s}$. The resolution of vertical velocity of all three instruments presented here is below $0.1 \mathrm{~m} \mathrm{~s}^{-1}$. Signal processing, noise filtering and error estimations for Doppler lidar, cloud radar and wind profiler can be found in Pearson et al. (2009); Görsdorf et al. (2015) and Lehmann (2012); Angevine (1997), respectively. In the following, different case studies are presented to demonstrate the manifold of possibilities enabled by this new combination of instruments.

\section{Case studies}

A combined vertical-velocity measurement with Doppler lidar, cloud radar and wind profiler from 30 July 2013 is shown

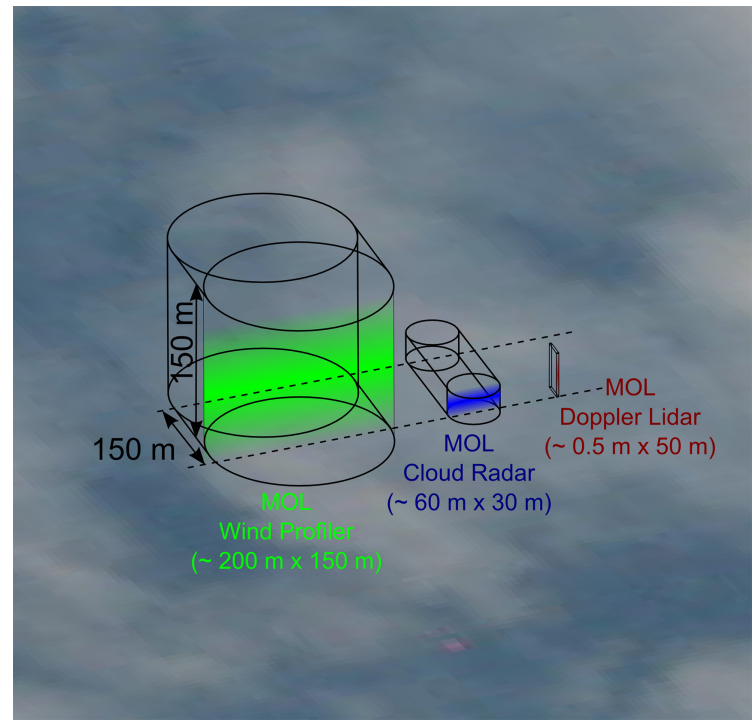

Figure 2. Comparison of observation volumes of Doppler lidar (red), cloud radar (blue) and wind profiler (green). Beam diameter times folded pulse length is given in brackets below the system names. The length interval of $150 \mathrm{~m}$, indicated by two dashed lines, is the displacement of the cloud during an integration time of $10 \mathrm{~s}$, when moving with an advection speed of $15 \mathrm{~m} \mathrm{~s}^{-1}$. In the background, a representation to scale of the altocumulus at $4000 \mathrm{~m}$ height is shown. In this figure, only the sizes of the observation volumes are shown. In reality, the observation volumes of cloud radar and Doppler lidar would overlap from about $1000 \mathrm{~m}$ height upwards. One pulse of the wind profiler fills a factor of $10^{4} \ldots 10^{5}$ more space than the Doppler lidar.

in Fig. 3. In the following Section different parts of this scene will be analyzed with respect to different aspects of vertical motions in the atmosphere.

The measurement shows a developing PBL with cumuli at the PBL top at about $1500 \mathrm{~m}$ height visible in the Doppler lidar SNR plots. These clouds are not visible in the cloud radar, due to their low signal and contamination with pollen and insects. From 11:30 UTC a convective system approaches producing rain. It is visible from this overview that the signal strengths of the different systems are completely disjunct, but 


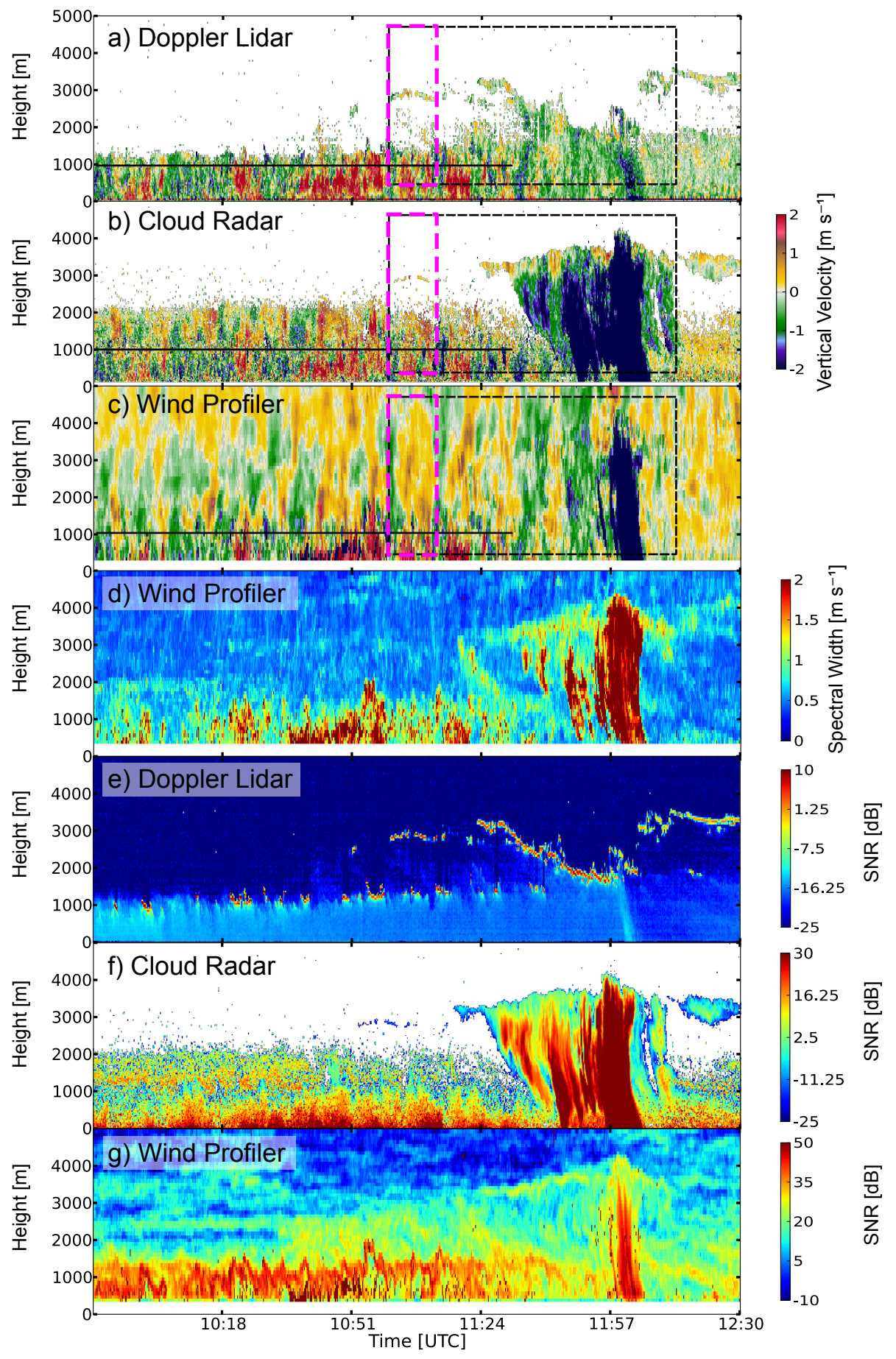

Figure 3. The combined measurements of Doppler lidar (a and e), cloud radar (b and f) and wind profiler (c, d and g) from 30 July 2013 are shown. Vertical velocities $(\mathbf{a}-\mathbf{c})$ and signal strenght $(\mathbf{e}-\mathbf{g})$ are shown for all instruments. For the wind profiler, additionally the width of the spectral peak is shown in $(\mathbf{d})$.

their vertical-velocity measurements overlap at cloud tops and in the PBL. In Fig. 3a-c, the straight black line marks the values from which the spectra in Fig. 4 were calculated. In the same figure, the pink dashed box marks the cloud stud- ied in Fig. 5 and the black dashed box marks the area for which a velocity feature classification was done in Fig. 6. 

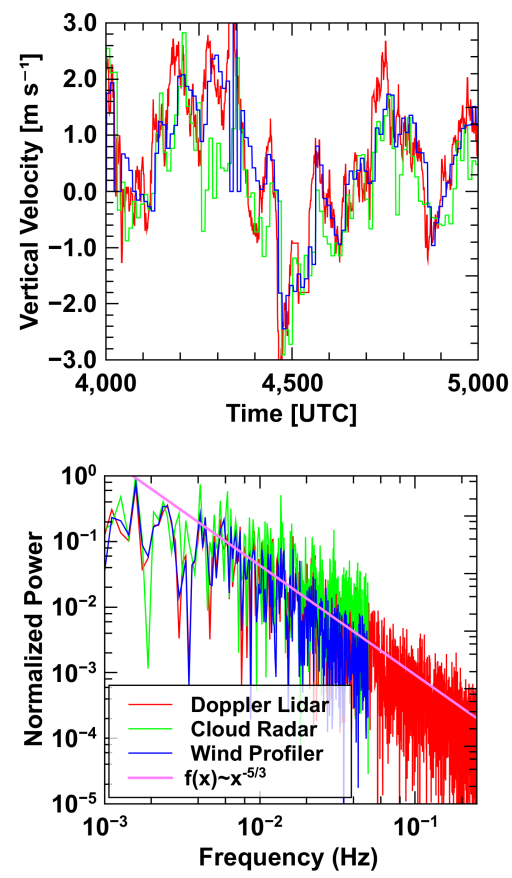

Figure 4. A combined vertical-velocity measurement from 30 July 2013, 09:45 to 11:15 UTC at $1000 \mathrm{~m}$ height (as indicated in Fig. 3 with a black line) is shown. Top panel shows a part of the verticalvelocity time series, the bottom panel shows the corresponding power spectra of the full time series.

\subsection{Observations of air motion, aerosols and biological scatterers in the boundary layer}

It is visible in Fig. 3 that the Doppler lidar, the cloud radar and the wind profiler all sense movements in the planetary boundary layer (PBL). The movements of the air are measured by the wind profiler (Fig. 3c). The Doppler lidar can derive them indirectly where aerosol particles are present to produce a backscatter signal (Fig. 3a). Since these aerosol particles have a very small size, in the range of $50 \mathrm{~nm}$ up to some microns, their fall speed relative to the surrounding air is negligible and the measurement is not biased by this effect. In the PBL the cloud radar also shows vertically moving targets, probably pollen and other big particles floating in the air. The combination of these targets is usually called atmospheric plankton and is a large source of uncertainty for the measurements of the cloud radar. The main source of error in this context is the fact that a single large object like an insect can dominate the complete signal return. The resulting noise can then obscure the signal from other smaller atmospheric scatterers. Live insects can even actively counteract the vertical motions induced by the atmosphere. (Geerts and Miao, 2005; Chandra et al., 2010) These measured velocity values are therefore more ambiguous than those of the Doppler lidar and the wind profiler.
The Doppler lidar is not strongly influenced by large scatterers like insects or pollen, because usually the background of small aerosol particles is big enough to dominate the signal. The wind profiler is not influenced strongly by insects, because they are small against the wavelength and the Bragg signal is usually sufficient to still dominate the signal return. Close to the ground, however, the signal of the wind profiler is sometimes disturbed (see, e.g., blue areas in Fig. 3 at $500 \mathrm{~m}$ height around 10:51 UTC). This disturbance is probably due to ground clutter or birds moving through the observation volume. The vertical-velocity signal of the three instruments along the black solid line in Fig. 3 is analyzed in Fig. 4. One can see from the bottom panel of the figure that the frequency response of all three instruments is very similar, despite the great technical differences and the different tracer targets involved. The noise level is slightly elevated in the cloud radar. The similarity between the spectra implies that all instruments correctly resolve the free turbulence in the boundary layer.

\subsection{Wave cloud}

A magnified portion of the updraft structure between 11:00 and 11:15 UTC from Fig. 3 is shown in Fig. 5. The Doppler lidar (Fig. 5a) shows the base of a liquid cloud at $2900 \mathrm{~m}$, forming within the updraft structure visible in the wind profiler measurements (Fig. 5c). Where large cloud droplets are present, the imprint of the updraft structure can also be partly seen in the cloud radar measurements (see Fig. 5b). The wind profiler also indicates subsidence regions at the edges of the layered cloud. This case highlights the special value of the wind profiler. The large-scale updraft is obviously the reason for the occurrence of the cloud layer at $2900 \mathrm{~m}$ height. From Doppler lidar or cloud radar one could infer the presence of an updraft, but only with the measurements of the wind profiler the detailed structure of this updraft can be recorded. It is also interesting to note that the signal sensitivities of the three instruments are completely different.

\subsection{Classification of vertical-velocity features in a complex atmospheric scene}

The combination of Doppler lidar, cloud radar and wind profiler allows the characterization of different vertical-velocity patterns. Small-scale turbulent motions within clouds are detected most easily with the Doppler lidar, big falling particles with the cloud radar and the motion of clear air around the clouds can be sensed with the wind profiler. Within the clouds the signal of the wind profiler is disturbed when large particles like rain drops are present (see Sect. 3.5). When comparing Fig. 3a and d, it is obvious that the wind profiler signal is broadened by small-scale turbulence (visible, e.g., at cloud tops) and by Rayleigh scattering at large particles (e.g., at 12:05 UTC). Spectral broadening can indeed be 
a)
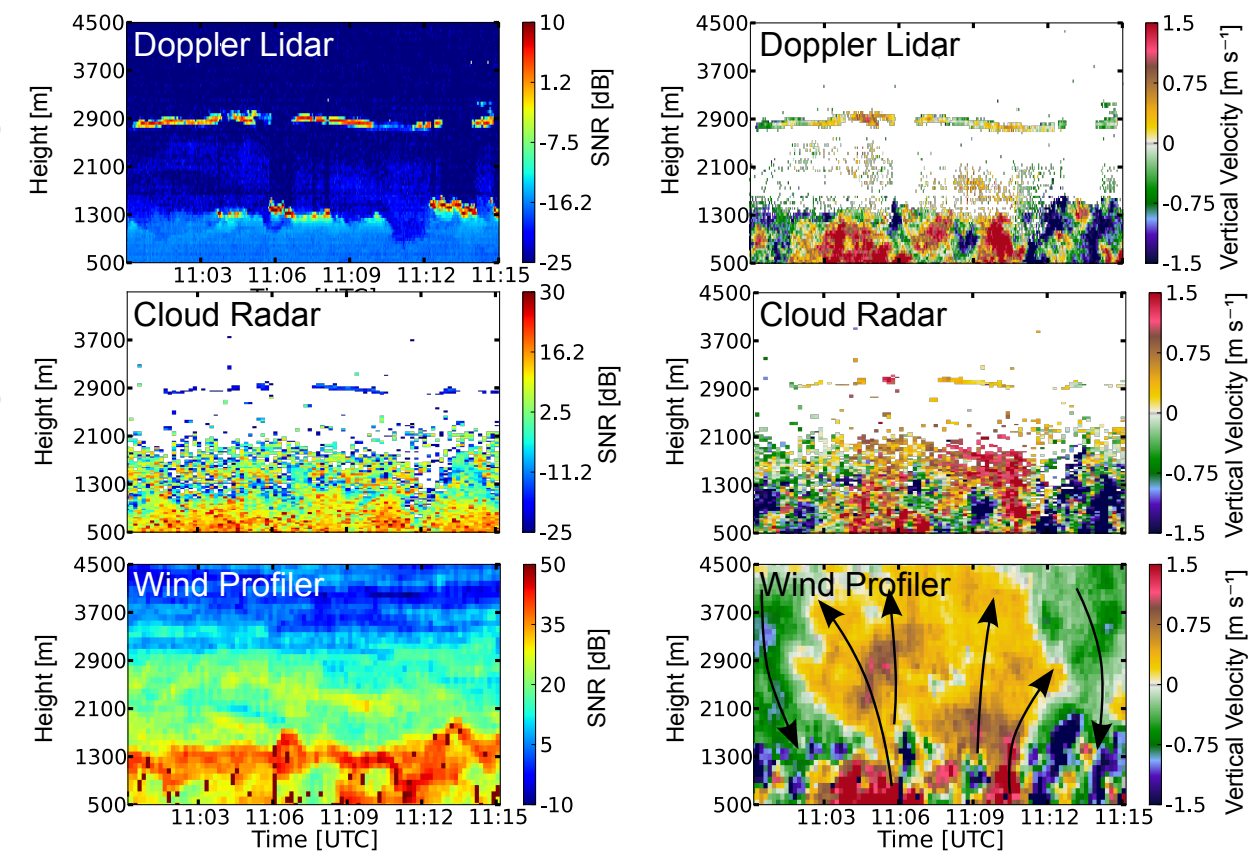

Figure 5. Magnified portion of Fig. 3 (pink dashed box, 11:00-11:15 UTC). SNR of each single instrument is shown in left column, vertical velocity on the right. The wind profiler gives unambiguous information about the vertical velocity of air in the vicinity of the cloud, which is detected by the Doppler lidar and partly by the cloud radar.
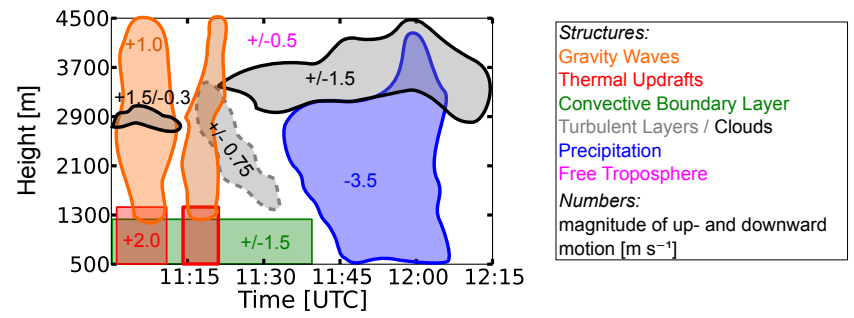

Figure 6. Features of vertical velocity are collected from the area marked in Fig. 3 with a black dashed box. The magnitude of detected vertical velocities is indicated with numbers, the different colors indicate different features described in the legend (Bühl, 2015).

caused by a variety of effects. For clear-air radars, the topic was discussed in detail by Hocking (1983).

On the basis of the combined measurements, in Fig. 6, a classification of vertical-velocity patterns has been put together manually. The figure shows that the combination of the three instruments is a unique way to coherently resolve and identify the different types of vertical motion in the troposphere. It is shown here that it is possible to provide a full picture of atmospheric motions without blank spaces. This feature classification has been assembled manually and is still quite coarse, so it is not yet applicable to a larger data set. However, such classification has not been done before and could, in principle, act complementary to other automated classification schemes like the Cloudnet target classification scheme (Illingworth et al., 2007). Since no other information apart from vertical velocity and spectral-width was used, it yields a completely new view focused solely on vertical motions in the atmosphere. In fact it is fascinating to see that such a classification is possible with only three independent data sets. Once automated, a classification like this could be a starting point for the detailed evaluation of, e.g., large-eddy simulation models which should be able to reproduce these vertical-velocity features.

\subsection{Quantification of terminal fall velocities in a precipitating cumulus cloud}

The apparent fall velocity of particles can be offset by vertical air motion and conceal or bias this information. The combination of Doppler lidar, cloud radar and wind profiler allows to retrieve the true terminal fall velocity of a particle relative to the surrounding air.

In Fig. 7 the vertical velocities measured by Doppler lidar and cloud radar are shown (top panel) before and after correction with the wind profiler measurements. For subtraction, the vertical wind field of the wind profiler is interpolated with a bilinear interpolation and subtracted from the Doppler lidar and cloud radar data. The latter data sets are not changed in time or height resolution. Without this correction particles in the cloud are found to move upwards and downwards. When the vertical velocity of air has been subtracted the true terminal fall velocity of the particles becomes visible. 


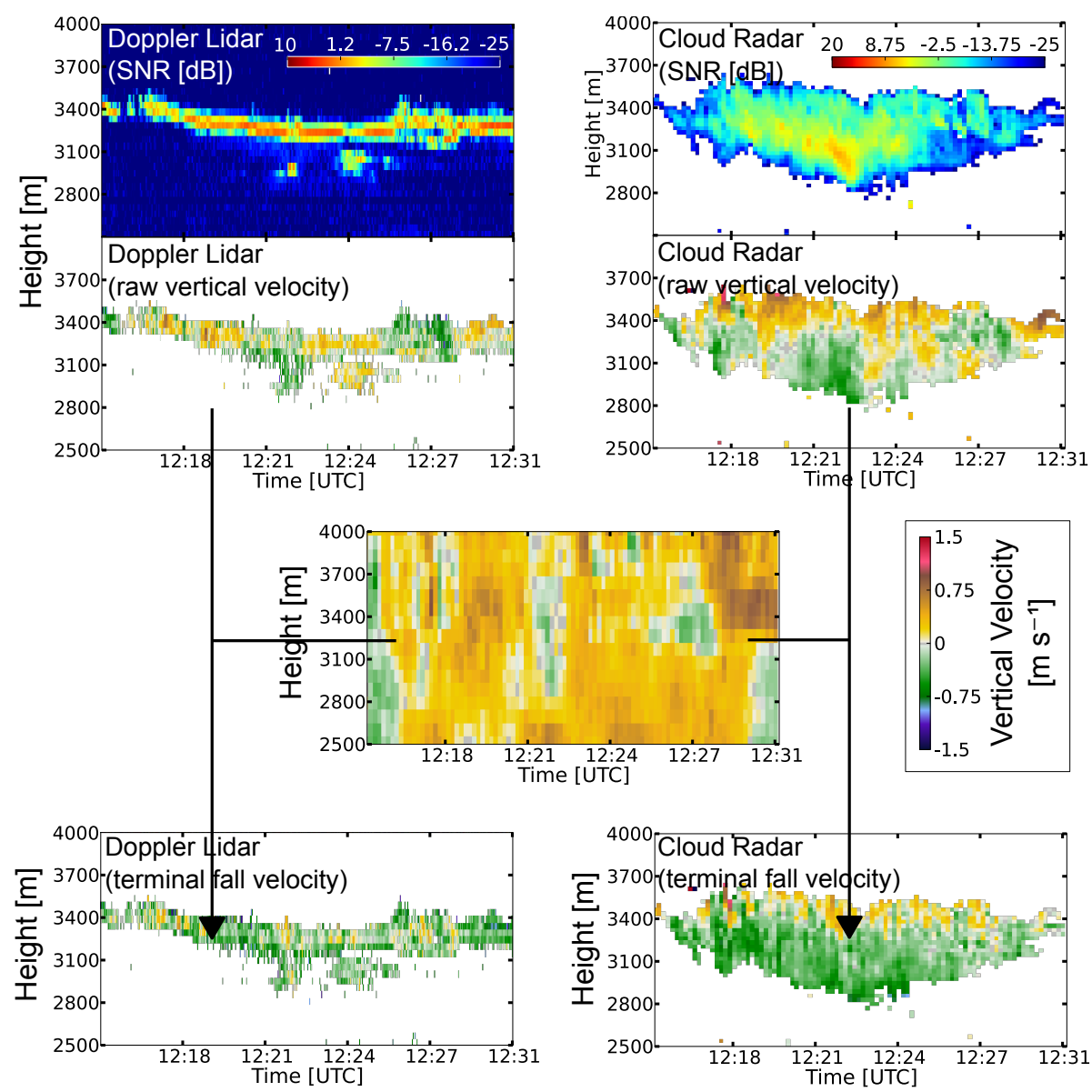

Figure 7. The vertical velocity of air measured by the wind profiler (center) is subtracted from the particle fall-velocities measured by Doppler lidar and cloud radar (top row). The resulting velocities (bottom row) are the terminal fall-velocity of the particles relative to the surrounding air. In the turbulent top layer, the turbulent motion is too fast and happens on scales which are too small to be correctly resolved by the wind profiler, resulting mostly in unrealistic upward velocities at the cloud top layer. Radiosonde data show a cloud-top temperature of $-3{ }^{\circ} \mathrm{C}$ and a cloud-base temperature of $0{ }^{\circ} \mathrm{C}$.

Some artifacts are still visible in the corrected velocity fields of Doppler lidar and cloud radar. At cloud top, e.g., positive vertical velocities of particles can be found even in the corrected vertical-velocity fields. The remaining error of the technique can be estimated by analyzing the remaining positive vertical velocities, which are unrealistic. The deviations above $0 \mathrm{~m} \mathrm{~s}^{-1}$ are limited to about $0.3 \mathrm{~m} \mathrm{~s}^{-1}$, except of some stronger outliers at 12:18 UTC. It is speculated that the vertical velocity has a strong vertical gradient at the top of the cloud layer. Hence, the subtraction of the wind profiler measurements is therefore not complete, because the cloud radar has a smaller height resolution than the wind profiler. The wind profiler measures a mean velocity in the top part of the cloud while the cloud radar can resolve the vertical velocity in detail. In the Doppler lidar measurements similar effects are visible, but in this case at cloud base. The Doppler lidar is strongly attenuated there, so the backscattered signal originates from a very confined height interval. Yet, in this way the Doppler lidar delivers information from the small, freshly activated droplets at cloud base. Those cannot be sensed by the cloud radar, because, as explained above, at cloud base the signal is governed by larger falling particles.

It is worth noting again that the cloud-radar verticalvelocities mentioned here are all reflectivity-weighted and therefore only represent the motion of a certain part of the particle spectrum. The correction itself, however, stays valid and could easily also be applied on a complete cloud radar spectrum. Such a spectrum can the be analyzed with established spectral analysis methods (Luke et al., 2010).

\subsection{Quantification of terminal fall velocities in a mixed-phase cloud layer}

In Fig. 8 a combined vertical-velocity measurement from 25 September 2013 is shown. It is visible from Fig. 8 that Doppler lidar, cloud radar and wind profiler show completely disjunct measurements in this cloud layer. Figure 9 shows the vertical-velocity values and the corresponding turbulent 
a)
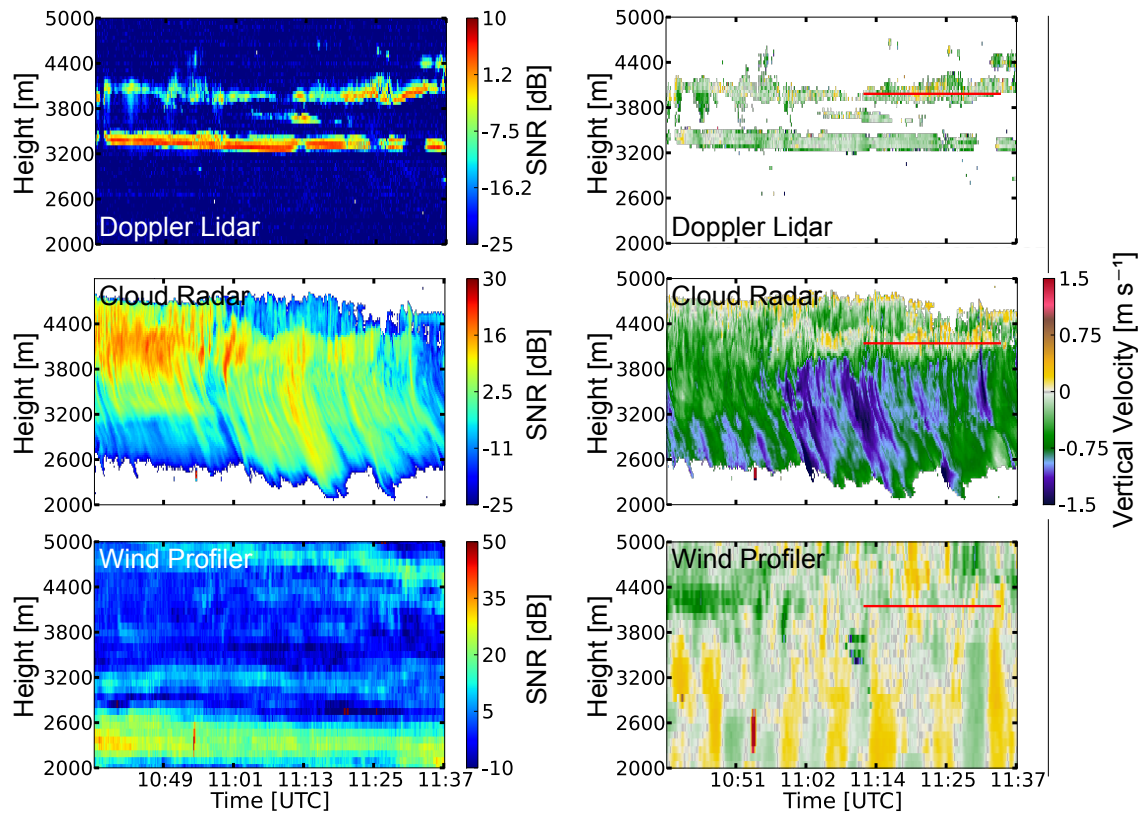

Figure 8. An example of vertical velocities measured in mixed-phase cloud layer recorded on 25 September 2013 at MOL. It is clearly visible that the information of Doppler lidar, cloud radar and wind profiler are mostly disjunct and represent turbulent motion in liquid layers (Doppler lidar), falling particles (Doppler lidar and cloud radar) and vertical air motion (wind profiler). The red line represents the vertical velocity values from which the turbulence spectra in Fig. 9 were computed. Radiosonde shows a cloud-top temperature of $-13^{\circ} \mathrm{C} .0^{\circ} \mathrm{C}$ is reached at $2000 \mathrm{~m}$ height.

spectra for the line indicated in Fig. 8. It is visible that only the Doppler lidar can resolve the turbulent motions at this cloud base, showing a decreasing spectrum in the range of high wave numbers. The properties of the falling particles (Fig. 8b) and the air motion (Fig. 8c) are sensed by cloud radar and wind profiler.

After subtraction of the vertical velocities measured by the wind profiler at the corresponding time and height interval, the true fall speed of the particles relative to the air becomes visible (see Fig. 10 and compare with Fig. 8). After this correction, fall streaks in the virgae are more coherent. Such a corrected fall velocity yields important information about particle size and shape. It could be used, for example, to derive the particles maximum diameter with methods such as those presented by (Mitchell, 1996; Heymsfield and Westbrook, 2010).

The wind-profiler vertical velocities itself are corrected by spectral separation of the wind-profiler and the cloud-radar spectra in order to remove the particle influence from the wind profiler measurements and get the pure vertical-wind information, similar to the method proposed by Gage et al. (1999). A detailed description of this method will be given elsewhere (paper in preparation). In the highly turbulent regions of the liquid cloud layers the mutual correction between Doppler lidar, cloud radar and wind profiler fails, because the temporal and spacial resolution of the cloud radar and wind profiler are not sufficient to resolve the small-scale turbulence.

Interesting to note is the sudden jump in fall velocity occurring at around 11:00 UTC. At this time, multiple turbulent layers are visible in the cloud radar at $3900 \mathrm{~m}$ and $4700 \mathrm{~m}$. Particles produced by the upper layer may grow faster, rime or aggregate in the lower layer and therefore show a higher fall speed compared to those before.

\section{Summary}

The combined observation of vertical-velocity patterns with a Doppler lidar, a $35 \mathrm{GHz}$ cloud radar and a UHF wind profiler has been demonstrated. For the first time, these three instruments were used to measure within the same measurement volume and with a temporal resolution smaller than $10 \mathrm{~s}$. It was shown that it is possible to characterize different kinds of vertical motions occurring at different scales, including gravity waves, thermal updrafts, turbulence at cloud base and falling particles. The terminal fall velocity of particles relative to the surrounding air could be retrieved by subtraction of the vertical velocity of clear-air from the apparent particle fall velocity. 

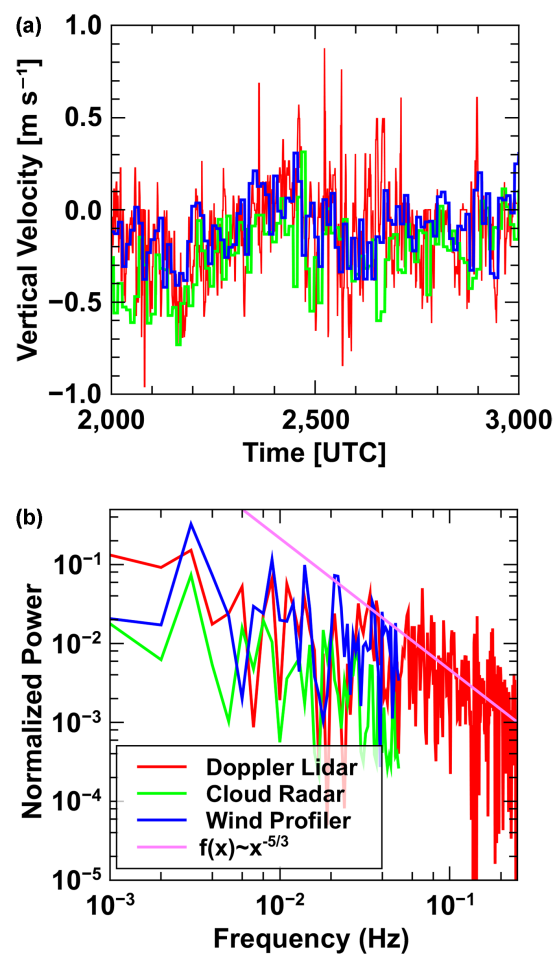

Figure 9. The vertical velocities (a) and their power spectra (b) are shown, taken at the red lines indicated in Fig. 8. It is clearly visible that only the Doppler lidar is able to sense the inertial subrange, where its power spectrum is close to the $f^{-5 / 3}$ line. The advantage of the Doppler lidar is also visible in (a), where fast changes of vertical velocity on time scales smaller than $10 \mathrm{~s}$ are visible only in the Doppler lidar measurements (red).

\section{Conclusion and discussion}

The combined vertical-velocity measurements yield unique information about the movements of small and big particles together with the true movement of the air. In the corrected particle fall velocities, systematic errors of about $0.3 \mathrm{~m} \mathrm{~s}^{-1}$ have been detected (see Fig. 7). This corresponds to the accuracy of the single instruments which is on the order of $0.1 \mathrm{~m} \mathrm{~s}^{-1}$. The big pulse volume of the wind profiler obviously poses problems if the small-scale variability is high, e.g., at turbulent cloud tops.

It was shown that the use of a wind profiler can fill the white spaces left on the vertical-velocity picture drawn by Doppler lidars and cloud radars. On the other hand, a Doppler lidar can detect cloud and aerosol particles, where cloud radar and wind profiler are not sensitive enough. Large-scale atmospheric motion becomes visible together with clouds and the extent and strengths of vertical-velocity fields can be studied independent of the presence of tracers, like aerosol particles or cloud droplets. a)

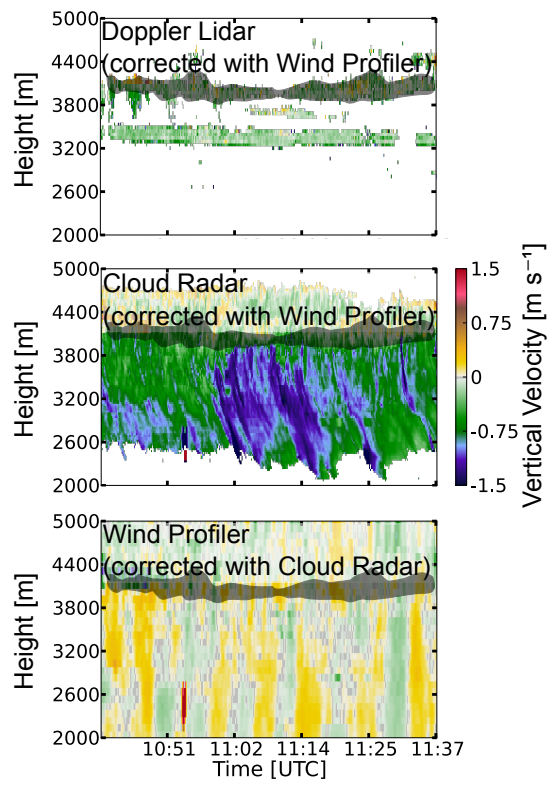

Figure 10. Demonstration of mutual vertical-velocity correction of the measurement shown in Fig. 8. A nearest-neighbor interpolation of the wind-profiler data was subtracted from the cloud-radar and Doppler lidar vertical velocities. The Doppler lidar is used to identify liquid layers (gray area). Inside and above these layers the subtraction procedure might be invalid because of several effects including liquid attenuation and small-scale turbulence that cannot be resolved by the wind profiler.

Acknowledgements. The research leading to these results has received funding from the European Union Seventh Framework Programme (FP7/2007-2013) under grant agreement no. 262254.

Edited by: A. Stoffelen

\section{References}

Angevine, W. M.: Errors in Mean Vertical Velocities Measured by Boundary Layer Wind Profilers, J. Atmos. Ocean. Tech., 14, 565-569, doi:10.1175/15200426(1997)014<0565:EIMVVM>2.0.CO;2, 1997.

Böhme, T., Hauf, T., and Lehmann, V.: Investigation of shortperiod gravity waves with the Lindenberg $482 \mathrm{MHz}$ tropospheric wind profiler, Q. J. Roy. Meteor. Soc., 130, 2933-2952, doi:10.1256/qj.03.179, 2004.

Bühl, J.: Combined lidar and radar observations of vertical motions and heterogeneous ice formation in mixed-phase layered clouds, Univ. Leipzig, available at: http://nbn-resolving.de/urn:nbn:de: bsz:15-qucosa-171998, 2015.

Bühl, J., Engelmann, R., and Ansmann, A.: Removing the laserchirp influence from coherent doppler lidar datasets by twodimensional deconvolution, J. Atmos. Ocean. Tech., 29, 1042 1051, doi:10.1175/JTECH-D-11-00144.1, 2012.

Bühl, J., Ansmann, A., Seifert, P., Baars, H., and Engelmann, R.: Towards a quantitative characterization of heterogeneous ice for- 
mation with lidar/radar: comparison of CALIPSO/CloudSat with ground-based observations, Geophys. Res. Lett., 40, 4404-4408, doi:10.1002/grl.50792, 2013.

Chandra, A. S.,Kollias, P., Giangrande, S. E., and Klein, S. A.: Long-Term Observations of the Convective Boundary Layer Using Insect Radar Returns at the SGP ARM Climate Research Facility, J. Climate, 23, 5699-5714, doi:10.1175/2010JCLI3395.1, 2010.

Gage, K. S., Williams, C. R., Ecklund, W. L., and Johnston, P. E.: Use of two profilers during mctex for unambiguous identification of bragg scattering and rayleigh scattering, J. Atmos. Sci., 56, 3679-3691, doi:10.1175/15200469(1998)055<2974:EREFSW>2.0.CO;2, 1999.

Geerts, B. and Miao, Q.: The Use of Millimeter Doppler Radar Echoes to Estimate Vertical Air Velocities in the Fair-Weather Convective Boundary Layer, J. Atmos. Oceanic Technol., 22, 225-246, doi:10.1175/JTECH1699.1, 2005.

Görsdorf, U., Lehmann, V., Bauer-Pfundstein, M, Gerhard, P., Dmytro, V., Vladimir, V., and Vadim, V.: A 35-GHz polarimetric doppler radar for long-term observations of cloud parameters - description of system and data processing, J. Atmos. Ocean. Tech., 32, 675-690, doi:10.1175/JTECH-D-14-00066.1, 2015.

Heymsfield, A. J. and Westbrook, C. D.: Advances in the Estimation of Ice Particle Fall Speeds Using Laboratory and Field Measurements, J. Atmos. Sci., 67, 2469-2482, doi:10.1175/2010JAS3379.1, 2010.

Hocking, W. K.: On the extraction of atmospheric turbulence parameters from radar backscatter Doppler spectra - I. Theory, J. Atmos. Terr. Phys., 45, 89-102, 1983.

Illingworth, A. J., Hogan, R. J., O'Connor, E. J., Bouniol, D., Delanoë, J., Pelon, J., Protat, A., Brooks, M. E., Gaussiat, N., Wilson, D. R., Donovan, D. P., Baltink, H. K., van Zadelhoff, G.J., Eastment, J. D., Goddard, J. W. F., Wrench, C. L., Haeffelin, M., Krasnov, O. A., Russchenberg, H. W. J., Piriou, J.-M., Vinit, F., Seifert, A., Tompkins, A. M., and Willén, U.: Cloudnet, B. Am. Meteorol. Soc., 88, 883-898, doi:10.1175/BAMS-88-6883, 2007.

Knight, C. A. and Miller, L. J.: Early radar echoes from small, warm cumulus: Bragg and hydrometeor scattering, J. Atmos. Sci., 55, 2974-2992, doi:10.1175/15200469(1999)056<3679:UOTPDM>2.0.CO;2, 1998.

Korolev, A. and Field, P. R.: The effect of dynamics on mixedphase clouds: theoretical considerations, J. Atmos. Sci., 65, 66, doi:10.1175/2007JAS2355.1, 2008.

Lane, S. E., Barlow, J. F., and Wood, C. R.: An assessment of a three-beam Doppler lidar wind profiling method for use in urban areas, J. Wind Eng. Ind. Aerod., 119, 53-59, doi:10.1016/j.jweia.2013.05.010, 2013.

Lehmann, V.: Optimal Gabor-Frame-Expansion-Based Intermittent-Clutter-Filtering Method for Radar Wind Profiler, J. Atmos. Oceanic Technol., 29, 141-158, doi:10.1175/2011JTECHA1460.1, 2012.

Luke, E. P., Kollias, P., and Shupe, M. D.: Detection of supercooled liquid in mixed-phase clouds using radar Doppler spectra, J. Geophys. Res.-Atmos., 115, 2156-2202, doi:10.1029/2009JD012884, 2010.
Mitchell, D. L.: Use of mass- and area-dimensional power laws for determining precipitation particle terminal velocities, J. Atmos. Sci., 53, 1710-1723, doi:10.1175/15200469(1996)053<1710:UOMAAD>2.0.CO;2, 1996.

Päschke, E., Leinweber, R., and Lehmann, V.: An assessment of the performance of a $1.5 \mu \mathrm{m}$ Doppler lidar for operational vertical wind profiling based on a 1-year trial, Atmos. Meas. Tech., 8, 2251-2266, doi:10.5194/amt-8-2251-2015, 2015.

Pearson, G., Davies, F., and Collier, C.: An Analysis of the Performance of the UFAM Pulsed Doppler Lidar for Observing the Boundary Layer, J. Atmos. Ocean. Tech., 26, 240-250, doi:10.1175/2008JTECHA1128.1, 2009.

Protat, A. and Williams, C. R.: The accuracy of radar estimates of ice terminal fall speed from vertically pointing Doppler radar measurements, J. Appl. Meteorol. Clim., 50, 2120-2138, doi:10.1175/JAMC-D-10-05031.1, 2011.

Simmel, M., Bühl, J., Ansmann, A., and Tegen, I.: Ice formation in altocumulus clouds over Leipzig: Remote sensing measurements and detailed model simulations, Geophys. Res. Abstr., EGU2014-6500, EGU General Assembly 2014, Vienna, Austria, 2014.

Strauch, R. G., Merritt, D. A., Moran, K. P., Earnshaw, K. B., and De Kamp, D. V.: The Colorado wind-profiling network, J. Atmos. Ocean. Tech., 1, 37-49, doi:10.1175/15200426(1984)001<0037:TCWPN>2.0.CO;2, 1984.

Tridon, F., Battaglia, A. Kollias, P., Luke, E., and Williams, C. R.: Signal Postprocessing and Reflectivity Calibration of the Atmospheric Radiation Measurement Program 915-MHz Wind Profilers, J. Atmos. Ocean. Tech., 30, 1038-1054, doi:10.1175/JTECH-D-12-00146.1, 2013.

Wandinger, U., Seifert, P., Engelmann, R., Bühl, J., Wagner, J., Schmidt, J., Pospichal, B., Baars, H., Hiebsch, A., Kanitz, T., Skupin, A., Pfitzenmaier, L., Heese, B., Althausen, D., and Ansmann, A.: Observations of aerosol-cloud-turbulence interaction with integrated remote-sensing instrumentation, 9th International Symposium on Tropospheric Profiling (ISTP), L'Aquila, Italy, 37 September 2012.

Weber, B. L. and Wuertz, D. B.: Comparison of rawinsonde and wind profiler radar measurements, J. Atmos. Ocean. Tech., 7, 157-174, doi:10.1175/15200426(1990)007<0157:CORAWP>2.0.CO;2, 1990.

Woodman, R. F. and Guillen, A.: Radar Observations of Winds and Turbulence in the Stratosphere and Mesosphere J. Atmos. Sci., 31, 493-505, doi:10.1175/15200469(1974)031<0493:ROOWAT>2.0.CO;2, 1974.

Zhang, D., Wang, Z., and Liu, D.: A global view of midlevel liquidlayer topped stratiform cloud distribution and phase partition from CALIPSO and CloudSat measurements, J. Geophys. Res.Atmos., 115, D00H13, doi:10.1029/2009JD012143, 2010.

Zhang, Y., Klein, S. A., Boyle, J., and Mace, G. G.: Evaluation of tropical cloud and precipitation statistics of community atmosphere Model version 3 using CloudSat and CALIPSO data, J. Geophys. Res.-Atmos., 115, D12205, doi:10.1029/2009JD012006, 2010. 